\title{
Lityum İyon Piller İçin Sn-Cu/rGO (İndirgenmiş Grafen Oksit) Anot Malzemelerin, Karakterizasyonu ve Elektrokimyasal Özellikleri
}

\author{
1*Mehmet UYSAL, ${ }^{2}$ Harun GÜL \\ ${ }^{1}$ Sakarya Üniversitesi, Mühendislik Fakültesi, Metalurji ve Malzeme Mühendisliği, Sakarya \\ ${ }^{2}$ Düzce Üniversitesi Gümüşova Meslek Yüksekokulu, Düzce
}

\section{$\ddot{O ̈ z}$}

Lityum iyon pilleri uzun kullanım ve raf ömrü, geniş kullanım sıcaklık aralığı, hızlı şarj edilebilirlik, yüksek enerji verimliliği gibi özellikleriyle son zamanlarda öne çıkan güç kaynaklarındandır. Grafite alternatif olarak kalay esaslı elektrot malzemeleri yüksek kapasite değerlerinden dolayı ilgi çekicidir. Ancak şarj/deşarj esnasında kalay esaslı elektrot malzemesinin karşılaştı̆̆ı en büyük problem hacim genleşmesidir. Bu problemi aşmaya yönelik olarak aktif veya inaktif malzeme ile birleştirilerek değiştirilebilir. $\mathrm{Sn}, \mathrm{Sn}-\mathrm{Cu}$ ve $\mathrm{Sn}-\mathrm{Cu} / \mathrm{rGO}$ tozları kimyasal indirgeme yöntemi ile $\mathrm{Li}$ iyon piller için anot malzemesi olarak üretilmiştir. $\mathrm{Sn}, \mathrm{Sn}-\mathrm{Cu}$ ve $\mathrm{Sn}-\mathrm{Cu} / \mathrm{rGO}$ tozların mikroyapı incelemeleri taramalı elektron mikroskobu (SEM) ile gerçekleştirilmiştir. Enerji dağılım X-1şınları spektroskopisi (EDS) ile Sn-Cu/rGO kompozit tozlarının elementel analizleri yapılmıştır.. Üretilen $\mathrm{Sn}, \mathrm{Sn}-\mathrm{Cu}$ ve $\mathrm{Sn}-\mathrm{Cu} / \mathrm{rGO}$ tozlar bakır akım toplayıcı üzerinde elektrot olarak hazırlanmış ve CR2016 düğme tipi hücreler kullanılarak $200 \mathrm{~mA} / \mathrm{g}$ sabit akım yoğunluğunda elektrokimyasal testleri gerçekleştirilmiştir. Elektrokimyasal test sonuçlarına göre, $\mathrm{Sn}-\mathrm{Cu} / \mathrm{rGO}$ kompozit anot malzemesi $\mathrm{Sn}$ ve $\mathrm{Sn}-\mathrm{Cu}$ elektrotlara göre daha iyi elektrokimyasal performans göstermiş ve 100 çevrim sonunda yaklaşık $430 \mathrm{mAh} / \mathrm{g}$ deşarj kapasitesi elde edilmiştir.

Anahtar Kelimeler: $\mathrm{Sn}$ anot, $\mathrm{Sn}-\mathrm{Cu}$ anot, indirgenmiş grafen oksit, Li-iyon pil

\section{Characterization and Electrochemical Properties of the Sn-Cu/Rgo (Reduced Graphene Oxide) Anode Materials for Lithium Ion Batteries}

\begin{abstract}
Li-ion batteries are the most studied power sources because of the properties of long cycle and shelf life, broad temperature range of operation, rapid charge capability and high coulombic and energy efficiency. Recently, there has been tremendous interest and effort to the synthesis of tin-based compounds as alternatives to graphite materials, with the aim of improving the capacity and energy density of lithium ion batteries. However, a large specific volume changing occurs during $\mathrm{Li}$ insertion and extraction reactions, which causes the electrode to fail by pulverization. Therefore, the main issue on the improvement of the Sn cycle performance is how to overcome the volume change and prevent the pulverization of particles. $\mathrm{Sn}, \mathrm{Sn}-\mathrm{Cu}$ and $\mathrm{Sn}-\mathrm{Cu} / \mathrm{rGO}$ powders were produced as anode material for $\mathrm{Li}$ ion batteries by chemical reduction method. Microstructural characterization of $\mathrm{Sn}, \mathrm{Sn}-\mathrm{Cu}$ ve $\mathrm{Sn}-\mathrm{Cu} / \mathrm{rGO}$ were carried out using scanning electron microscopy (SEM) Elemental analyses of $\mathrm{Sn}-\mathrm{Cu} / \mathrm{rGO}$ composite powders were performed using energy dispersive X-ray spectroscopy (EDS). Produced $\mathrm{Sn}, \mathrm{Sn}-\mathrm{Cu}$ ve $\mathrm{Sn}-\mathrm{Cu} / \mathrm{rGO}$ anode materials were prepared as an electrode on the copper current collector and electrochemical tests were carried out using CR2016 button cells at $200 \mathrm{~mA} / \mathrm{g}$ constant current density. According to the electrochemical test results, $\mathrm{Sn}-\mathrm{Cu} / \mathrm{rGO}$ composite anode material showed better electrochemical performance than $\mathrm{Sn}$ and $\mathrm{Sn}-\mathrm{Cu}$ anode materials and discharge capacity of about $430 \mathrm{mAh} \mathrm{g}$ was obtained after 100 cycles.
\end{abstract}

Keywords: $\mathrm{Sn}$ anode, $\mathrm{Sn}-\mathrm{Cu}$ anode, reduced graphene oxide, Li on battery,

\section{GİRIŞ}

Son yıllarda teknolojideki hızlı gelişmeler ve yakın gelecek için kurgulanan stratejiler nedeniyle enerjiye olan ihtiyaç her geçen gün artmaktadır. Uygarlığın başlangıcından beri düzenli ve konforlu hayat standardını sağlayabilmek için enerji kaynakları sürekli araştırılmış ve enerji kaynağı olarak da özellikle fosil yakıtlar, nükleer enerji ve güneş enerjisi gibi kaynaklar kullanılmıştır. Rezervleri gün geçtikçe azalan fosil yataklarının hızla tüketilmesi; küresel 1sınma ve hava kirliliği gibi çevre sorunlarının büyük boyutlara ulaşmasına neden olmuş, böylece daha ucuz, çevre dostu ve güvenli alternatif enerji kaynaklarına olan ilgi daha da artmıştır $[1,2]$. 
Yenilenebilir enerji kaynaklarının en önemli alanlarından bir tanesi de özellikle enerji depolama konusudur. Taşınabilir elektronik cihazlar, iletişim cihazları, bilgisayar hafiza sistemleri, medikal cihazlar (insan vücuduna yerleştirilen minik devreler), elektrikli hibrit araçlar ve sensörler çalışabilmek için sürekli olarak enerjiye ihtiyaç duymaktadırlar. Bu nedenle, enerji depolamaya olan gereksinimler sürekli olarak artmaktadır. $\mathrm{Bu}$ gelişmelere paralel olarak düşük boyutlarına oranla yüksek spesifik enerjiye, yüksek enerji depolama kapasitesine ve yüksek çevrim sayısına sahip olan tekrar doldurulabilir lityum piller, son dönemde üzerinde büyük bir titizlikle çalışılan alternatif enerji kaynağ 1 haline gelmiştir. Lityum iyon piller yüksek enerji yoğunluğuna sahip olmaları sebebi ile cep telefonları, dizüstü bilgisayarlar gibi modern elektronik cihazları için enerji kaynağı olarak en çok kullanılan pillerdir [1-4]. Elektronik cihazlarda yüksek kapasiteli pillere olan ihtiyacın artması, yüksek enerji kapasitesine sahip lityum iyon pilleri için yeni malzemeler geliştirme ihtiyacını beraberinde getirmiştir [2]. Lityum iyon piller her ne kadar umut verici sistemler olsa da halen optimize edilmesi gereken birçok hususu da içermektedir. Bunlara örnek olarak, uzun dönemde pillerin hücre birimlerinin kararlılığını koruması, şarj ve deşarj esnasında ortaya çıkan ısının kontrolü, yüksek kalite ve düşük maliyet gibi hususlar örnek olarak verilebilir [1].

Yüksek kapasiteli Li-iyon pil uygulamaları için lityum ile reaksiyona giren birçok metal bulunmaktadir. Grafitin anot malzemesi olarak tercih edilmesi yanı sıra bir takım metaller de anot malzemesi olarak çalışılmıştır. Bunun en temel nedeni ise grafitten çok daha yüksek kapasitelere sahip olmalarıdır. Bu sebeple lityum ile alaşım yapan metaller yeniden şarj edilebilir lityum pilleri için anot malzemesi olarak oldukça dikkat çekmektedirler $[2,5,6]$. Bu alternatif anot malzemeleri arasında yüksek spesifik kapasiteye sahip olan Al, Si, Sb ve Sn gibi metaller ve bu metallerin lityum ile alaşım yapabilen bileşikleri öne çıkmaktadır [6, 7]. Özellikle kalay ve silisyum üzerinde yapılan çalışmalarda her bir silisyum ve kalay atomunun elektrokimyasal olarak 4,4 Li atomu ile birleşmesi sırasında 990 mAhg-1 ve 4199 mAhg1 lık bir enerjinin ortaya çıktığı görülmüştür. Ancak bu malzemelerin çevrim ömürleri oldukça zayıftır. Bunun nedeni ise bu malzemelerin lityum ile reaksiyonu sonrasında çözünmeye, parçalanmaya ve çatlamaya uğramalarıdır. Bununla birlikte, lityum alaşımları ile üretilen anot malzemelerinde şarj ve deşarj esnasında büyük hacimsel değişimlerin meydana geldiği ve belirli bir çevrimden sonra da anotta çatlakların ve kırılmaların ortaya çıktığı gözlemlenmiştir. Bunun yanında metalik elektrotlar ile karşılaştırıldığında LixM lityum alaşımları oldukça iyonik karakterli olduklarından kırılganlıkları da fazladır. Buna bağlı olarak meydana gelen mekanik gerilmeler ve hacim genleşmeleri, mekanik kararlılığın azalmasına neden olur. Elektrotta çatlak ve tozlaşma problemi ve partiküller arasında elektronik kontak kayıları meydana gelir. $\mathrm{Bu}$ durum, elektrodun çevrim ömrünü ve mekanik kararlılığını azaltmaktadır $[1,8,9]$.

Günümüzde yapılan anot malzemesi üretim çalışmaları ağırlıklı olarak aktif-inaktif' kompozitler düşüncesi göz önüne alınarak, intermetalik nano kompozitler üzerinde yoğunlaşmaktadır. $\mathrm{Bu}$ tür malzemelerin temel niteliğinin ise elektrokimyasal çevrim boyunca anot malzemesinin hacimsel olarak genleşmesi sırasında herhangi bir hasarın ortaya çıkmasının engellenmesi şeklinde düşünülebilir $[1,10]$. Yapılan araştırmaların birçoğunda ise nano kristal olarak elde edilen aktif fazların kristalografik yapısının kararlılığını koruduğu, yüksek oranda hacimsel değişmelerden anot malzemesinin etkilenmemesini sağladiğı görülmüştür. Bu olumsuz yönler; lityuma ev sahipliği yapan elektrot malzemesinin partikül boyutu küçültülerek, tek fazlı malzemeler yerine çok fazlı malzemeler kullanılarak ya da intermetalik bileşikler kullanılarak giderilebileceği birçok araştırma grubu tarafından gösterilmiştir. $\mathrm{Al}, \mathrm{Si}, \mathrm{Sb}$ ve $\mathrm{Sn}$ metallerinin birçok intermetalik bileşiklerinin lityumu depolama kapasiteleri saf metalinkine yakın olup daha yüksek çevrimsel kararlılık gösterirler $[1,7,10]$.

Grafen, bir atom ölçekli petek kafes örgüsüne sahip karbon atomlarından oluşan 2 boyutlu bir yapıdır. 2 boyutlu yapıya sahip olması her atomun yüzey atomu olarak davranması anlamına gelmektedir [11]. 2 boyutlu bir yapının termodinamik olarak kararsız olacağı düşünülen bu yapı 2004 yılında Novaselov ve arkadaşları tarafindan mekanik soyma (exfoliation) yöntemi ile başarılı bir şekilde üretilmiştir. Üretiminden bu yanı gösterdiği olağanüstü özellikler sayesinde grafen, günümüzde nanoelektronik, enerji depolama ve dönüşümü, sensörler ve katalizörler gibi birçok uygulamada umut verici bir malzeme haline gelmiştir [12-14].

\section{DENEYSEL ÇALIŞMALAR}

Kalay nano partiküllerini üretmek için $0,2 \mathrm{~g}$ $\mathrm{SnCl}_{2} \cdot 2 \mathrm{H}_{2} \mathrm{O}$ manyetik bir karıştırıcı yardımıyla 30 dakika boyunca hidroksit oluşmayacak şekilde kontrollü bir şekilde distile edilmiş suda çözündürülmüştür. Sonrasında $0.15 \mathrm{~g}$ sodyum bor hidrür karışımın içerisine oda sıcaklığında yavaş bir şekilde ilave edilmiştir. $\mathrm{NaBH}_{4}$ ilavesinden sonra şeffaf görünümde olan çözelti siyah renge dönüşmüştür. $\mathrm{Bu}$ durum partikül oluşumunu göstermektedir. Buna takiben siyah çözelti 
filtrelenmiş, yıkanmış ve $40{ }^{0} \mathrm{C}$ 'de 12 saat boyunca vakum etüvde kurutulmuştur.

$\mathrm{Sn}-\mathrm{Cu}$ alaşım tozlarını üretmek için ise $\mathrm{SnCl}_{2} \cdot 2 \mathrm{H}_{2} \mathrm{O}$ ve $\mathrm{CuCl}_{2} \cdot 2 \mathrm{H}_{2} \mathrm{O}$ tuzları birlikte saf su içerisinde çözündürülmüştür. Kalay ve bakır tuzları tamamiyle çözündürüldükten sonra çözeltinin içine $\mathrm{NaBH}_{4}$ çözeltisi damla damla ilave edilmiştir. NaBH4 ilave edilirken, çözelti hızlı bir şekilde manyetik karıştırıcı ile oda sıcaklığında karıştırılmıştır ve çözeltinin pH'ı 12-13 arasındadır. Tüm metal iyonlarının indirgenmesinden emin olabilmek için fazla miktarda $\mathrm{NaBH}_{4}$ çözeltisi kullanılmıştır.
$\mathrm{Sn}-\mathrm{Cu} / \mathrm{rGO}$ kompozit nano tozlarını üretebilmek için ise $\mathrm{SnCl}_{2} .2 \mathrm{H}_{2} \mathrm{O}, \mathrm{CuCl}_{2} .2 \mathrm{H}_{2} \mathrm{O}$ ve grafen oksit içeren bir çözelti kullanılmıştır. Grafen oksit öncelikle ultrasonik homejinizatör yardımıyla su içerisinde dağıtılmıştır. Daha sonra $\mathrm{SnCl}_{2} .2 \mathrm{H}_{2} \mathrm{O}$ ve $\mathrm{CuCl}_{2} \cdot 2 \mathrm{H}_{2} \mathrm{O}$ tuzları ilave edilmiştir. Sonrasında ise, tüm kimyasallar $0{ }^{0} \mathrm{C}^{\prime}$ de $\mathrm{NaBH}_{4}$ ile indirgeniştir. Metal iyonlarının ve grafen oksitin indirgenmesinden sonra tozlar filtrelenmiş, yıkanmış ve vakum altında kurutulmuştur. $\mathrm{Sn}-\mathrm{Cu} / \mathrm{rGO}$ kompozit malzemelerin üretim şeması Şekil 1'de verilmiştir.
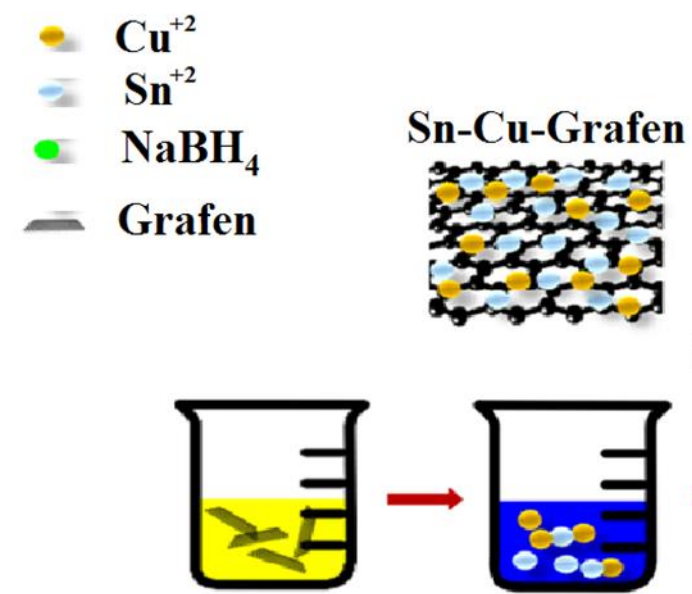

\section{Grafen Oksit Ultrasonik $\mathbf{S n C l}_{2}$ $\mathrm{CuCl}_{2}$}

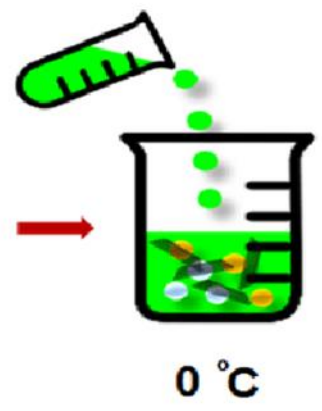

Manyetik Karıştırıcı

Şekil 1 Sn-Cu rGO kompozit malzemelerin üretim şeması

Taramalı elektron mikroskopu (SEM), kalay, $\mathrm{Sn}-\mathrm{Cu}$ ve $\mathrm{Sn}-\mathrm{Cu} / \mathrm{rGO}$ tozlarının yüzey morfolojilerini incelemek adına kullanılmıştır. Tozların kimyasal kompozisyonlarını $\mathrm{X}$-ışını difraksiyon paternlerinden belirlemek için $\mathrm{Cu} \mathrm{K} \alpha$ radyasyonlu Rigaku D/MAX 2000 X-1şını difraktometresi kullanılmıştır.

$\mathrm{Sn}, \mathrm{Sn}-\mathrm{Cu}$ ve $\mathrm{Sn}-\mathrm{Cu} / \mathrm{rGO}$ tozları, PVDF bağlayıcı ve karbon siyahı ağırlıkça 7:2:1 oranında karıştırılmış ve N-metil-2-pirolidinon (NMP) çözeltisi içerisinde çözündürülmüştür. Karışım homojen bir macun haline geldiğinde, macun bir bakır folyoyla bir doktor blade kullanılarak kaplanmış ve bunu takiben $120^{\circ} \mathrm{C}^{\prime} \mathrm{de} 12$ saat vakumlu bir firında kurutulma işlemine tabi tutulmuştur.

Elde edilen kompozit anot malzemelerin performans testlerinde test hücresi olarak CR2016 tipi şarj edilebilir lityum iyon piller kullanılmıștır. Pil performansının belirlenmesi için kullanılacak olan CR2016 tipi lityum iyon test hücreleri Ar gazı ile doldurulmuş MBraun marka glove box içerisinde üretilmişlerdir. Pillerde kullanılan referans elektrot lityum metali hava ve nem ile karşılaştığında çok hızlı şekilde korozyona uğradığı için glove box sisteminin kullanılması gereklidir. Çalışma için kullanılan sistemde oksijen ve nem değerlerinin her ikisi de 0,5 ppm altında tutulmuştur. Test hücrelerinde lityum metali referans elektrotuna karş1 mevcut çalışmada üretilmiş olan $\mathrm{Sn}, \mathrm{Sn}-\mathrm{Cu}$ ve $\mathrm{Sn}$ $\mathrm{Cu} / \mathrm{rGO}$ kompozit elektrotlar kullanılmıştır. Elektrotlar arasındaki iyonik iletkenliği sağlaması amacı ile kullanılan elektrolit \% 50 dimetil karbonat ve \% 50 etilen karbonat içerisinde çözünmüş LiPF6 tuzundan meydana gelmektedir. Elektrotların temasını önleyen ve iyonik iletkenliğe izin veren mikro gözenekli polipropilen Cellgard separatör kullanılmıştır. CR2016 tipi buton pil kasasına dizilen pil bileşenleri bir hidrolik pres ve CR2016 piller için üretilmiş bir kalıp yardımıyla kilitlenmiş ve elektrokimyasal testler içini buton pil şeklinde hazır hale getirilmiştir. Ayrıca, galvanostatik şarj/deşarj testleri için MTI BST8-MA tipi elektrokimyasal analiz cihazı kullanılmıştır. Çalışmada bu teknikle test edilen elektrotların tümü $0,02-1,5 \mathrm{~V}$ potansiyel aralığında, akım değeri sabit tutularak test edilmiştir. $\mathrm{Bu}$ çalışmada çevrimsel voltametri testlerini 
uygulamak için Gamry Reference 3000 tipi potansiyostat cihazı kullanılmıştır. Üretilen anotlar ve çevrimsel voltametri tekniği ile $0,02-1,5 \mathrm{~V}$ aralığında, $0,5 \mathrm{mV} / \mathrm{s}$ tarama hızlarında test edilmiştir.

\section{SONUCLAR TARTIŞMA}

Kimyasal indirgeme yöntemi ile elde edilen $\mathrm{Sn}, \mathrm{Sn}$ $\mathrm{Cu}$ ve $\mathrm{Sn}-\mathrm{Cu} / \mathrm{rGO}$ elektrot malzemelerin SEM görüntüleri Şekil 2'de verilmiştir. Şekil $2 a$ ve $2 b$ SEM görüntülerine bakıldığında kalay ve kalay bakır tozların morfolojisi küresele yakın olduğu görülmektedir. Kalay tozlarının boyutu yaklaşık 50-
$100 \mathrm{~nm}$ arasında değişmektedir. Kalay tozlarının boyutları homojen olarak dağılım göstermektedir. $\mathrm{Sn}-\mathrm{Cu}$ tozların boyutları saf kalay tozların boyutlarına göre daha iri görülmektedir. Şekil 2c'de verilen $\mathrm{Sn}-\mathrm{Cu} / \mathrm{rGO}$ kompozit malzemelerin SEM mikroyapıları incelendiğinde ise geçirgen indirgenmiş grafen oksit tabakalarının arasına metalik tozların başarılı bir şekilde dekore edildiği görülmektedir. Küresel olarak biriken $\mathrm{Sn}-\mathrm{Cu}$ partiküllerinin boyutlarında azalma ile birlikte beklendiği gibi grafen oksitlerin homojen bir şekilde matris yüzeyine dağıldığını ifade etmek yanlış olmayacaktır.

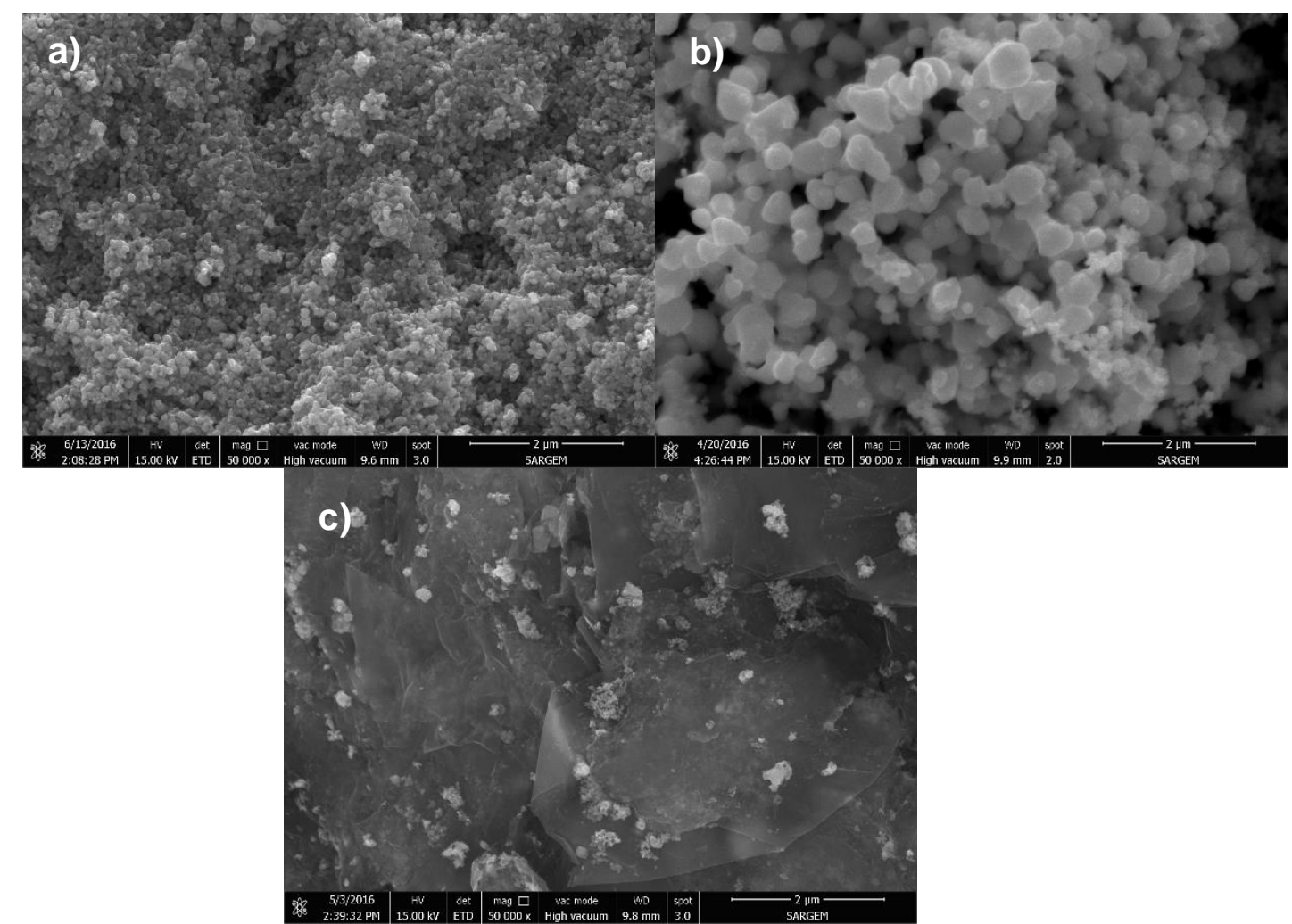

Şekil 2. Sn, Sn-Cu ve Sn-Cu/rGO elektrotların SEM görüntüleri; a) Sn, b) Sn-Cu c) Sn-Cu/rGO

$\mathrm{Sn}-\mathrm{Cu} / \mathrm{rGO}$ elektrot malzemelerin yüksek büyütmedeki SEM görüntüleri Şekil 3a'da verilmiştir. Sn ve $\mathrm{Cu}$ tozları indirgenmiş grafen oksit tabakaların yüzeyinde homojen dağılım göstermişlerdir. EDS analizi ile yapı içerisinde bulunan elementlerin dağılımı ve elementlerin yap1 içerisindeki oranları tespit edilmiştir. Literatürde de benzer çalışmalarda da yapı içerisindeki elementlerin nicelik ve nitelik olarak tespiti EDS analizi ile gerçekleştirilmiştir. Sn-Cu/rGO elektrotların yüzeyiden EDS analizi alınmıştır. EDS analizi sonucu şekil 3b'de verilmiştir. Şekil $3 b$ incelendiğinde $\mathrm{Sn}$ ve $\mathrm{Cu}$ elementlerinin yapı içerisinde homojen dağıldığı açıkça görülmektedir. Yap1 içerisinde görülen karbon elementi banyo çözeltisine ilave edilen indirgenmiş grafen oksitten kaynaklanmaktadır. SEM sonuçları ve EDS sonuçları birbirlerini desteklemektedirler. Bakır ve indirgenmiş grafen oksitin sahip olduğu plastik deformasyon özellikleri ile kalayda çevrim sırasında oluşan yüksek gerilmenin matriks boyunca dağıtılacağı ve bu sayede tozların parçalanma davranışını engelleyeceği düşünülmüştür[15]. Ayrıca bu iletken katkıların, elektrotun iletkenliğini arttırarak elektrottaki yük transferinde arttırması beklenmiştir. 


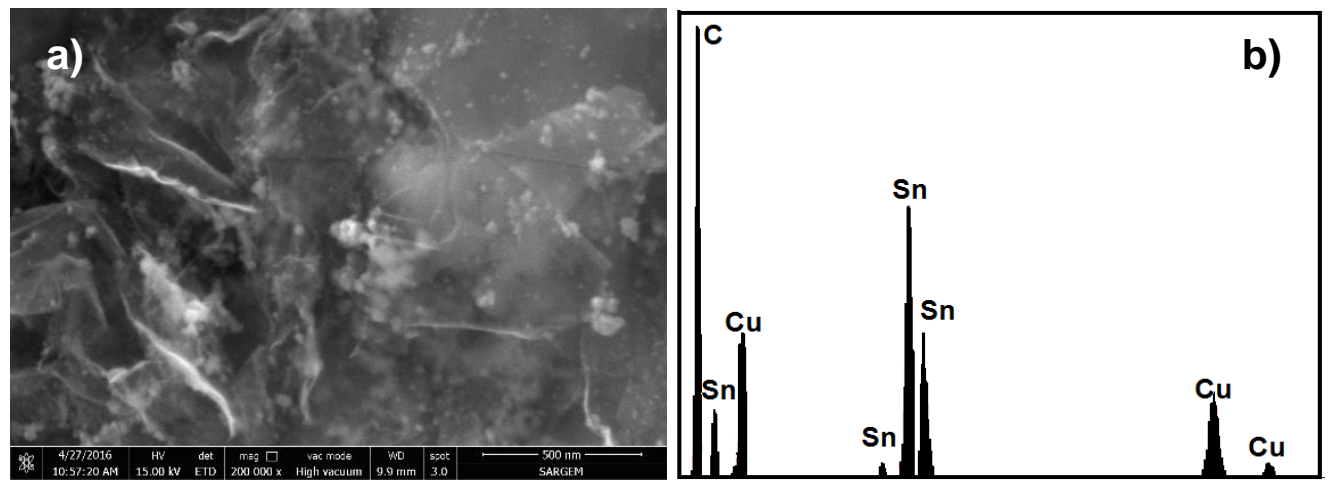

Şekil 3. Sn-Cu/rGO kompozit elektrotlarin SEM görüntüleri a)yüksek büyütme ve b) EDS analizi

Yarım hücre içerisinde gerçekleştirilen $\mathrm{Sn}-\mathrm{Cu} / \mathrm{rGO}$ kompozit elektrotun ilk beş çevrim CV eğrileri, anodun elektrokimyasal reaksiyon mekanizmalarını daha iyi anlamak amacıyla yapılmış ve Şekil 4'de verilmiştir. Sn-Cu/rGO kompozit elektrotların gösterdiği pikler lityum iyonlarının elektrot yapısına girişi ve yapıdan ayrılması ile iliş̧ilendirilmiştir. $\mathrm{Sn}-\mathrm{Cu} / \mathrm{rGO}$ kompozit elektrotların $\mathrm{CV}$ eğrilerinin katodik bölümünde, ilk çevrim boyunca $0,6 \mathrm{~V}-0,7$ $\mathrm{V}$ arasında gözlemlenen pik, elektrolitin bozunmasına ve tersinmez bir reaksiyon olan katı elektrolit ara yüzeyi (SEI) tabakasının oluşmasına işaret eder ve sonraki çevrimlerde kaybolmaktadır. Literatür çalışmalarına baktığımızda, Li iyon piller için anot malzemesi $\mathrm{SnO} 2$ kullandığımızda, yaklaşık 0,8 V'da geri dönüşümsüz olan $\mathrm{SnO} 2$ 'nin $\mathrm{Sn}$ metaline redüksiyonu ve katı elektrolit arayüzeyi (SEI- Li2O tabakası) oluşumu ilk çevrimde büyük bir geri dönüşümsüz kapasiteye yol açmaktadır $[16,17]$.

Şekil 4'den Li'nin, Sn ile alaşımlama ve dealaşımlama reaksiyonlarının 0,15 ve $0.4 \mathrm{~V}$ arasında meydana geldiği görülmektedir. 0,18 ve $0,22 \mathrm{~V}$ değerinde olan anodik pik LixSn'nin dealaşımlamasını göstermektedir. $0,15 \mathrm{~V}$ değerinde olan katodik pik ise LixSn in de-alaşımlamasını göstermektedir $[18,19]$. İlk çevrimden sonra devam eden çevrimlerde, ilk çevrimde meydana gelen, sonraki çevrimlerde devam eden bakırın katalitik etkisinden dolayı akım değeri yükselmiştir. AkımVoltaj eğrilerinden de görüldüğü gibi bütün çevrimler çok az fark olsa da birbirine çok benzemektedir. Bunun anlamı lityum ile kalayın alaşımlama de-alaşımlama esnasında oluşan reaksiyonların her döngüde kararlı olduğunu söyleyebiliriz. Anodun alaşımlama ve dealaşımlama reaksiyonlarının aktif olarak gerçekleştiği görülmektedir.

Şekil 5'de $\mathrm{Sn}, \mathrm{Sn}-\mathrm{Cu}$ ve $\mathrm{Sn}-\mathrm{Cu} / \mathrm{rGO}$ tozları ile hazırlanmış elektrotların 1., 2., 50. ve 100. çevrim için voltaj-kapasite eğrilerini gösterilmektedir. Şekilden de görüldüğü gibi saf $\mathrm{Sn}, \mathrm{Sn}-\mathrm{Cu}$ ve $\mathrm{Sn}$ -
$\mathrm{Cu} / \mathrm{rGO}$ elektrotlarının ilk deşarj kapasiteleri sirasiyla 970, 745 ve $680 \mathrm{mAhg}^{-1}$ olarak elde edildiği anlaşılmaktadır. Görüldüğü üzere en yüksek birinci deşarj kapasiteleri $\mathrm{Sn}, \mathrm{Sn}-\mathrm{Cu}$ elektrot malzemelerinde elde edilmiştir.

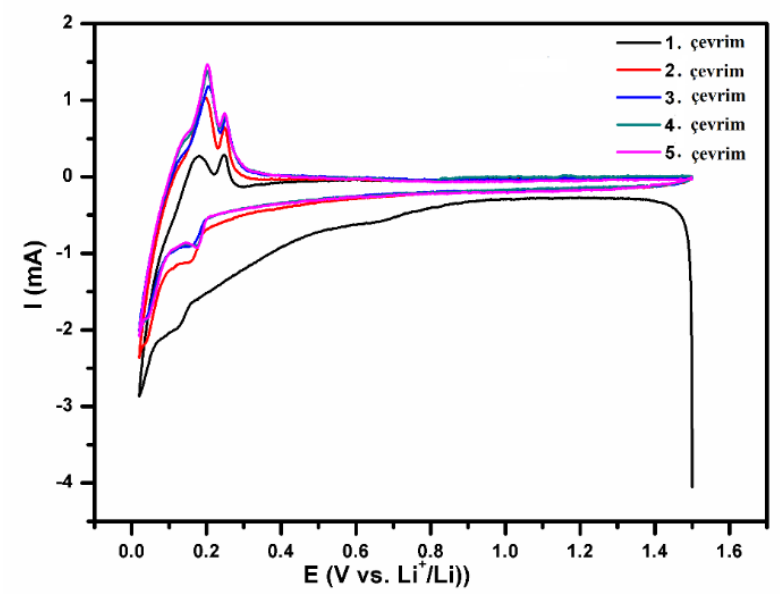

Şekil 4. Sn-Cu/rGO kompozit malzemenin çevrimsel voltametri analiz sonuçları

Saf kalay ve $\mathrm{Sn}-\mathrm{Cu}$ elektrotlarda, ilk çevrim sonunda elektrolitin bozularak, elektrot ile elektrolit arasında oluşan katı oksit ara yüzey (SEI) film tabakasından dolayı kapasite düşüşü meydana gelmiştir. Devam eden çevrimlerde deşarj ve şarj arasındaki kapasite kaybı giderek azalmıştır. Şekilden de görüldüğü gibi Sn anot malzemenin ilk deşarj ve şarj kapasitesi sırasıyla 970 ve 570 mAhg-1, kulombik verimlilik ise \%58 olarak ölçülmüştür. $\mathrm{Sn}-\mathrm{Cu}$ anot malzemesi için ilk deşarj ve şarj kapasiteleri sırasıyla 745ve 490 mAhg-1, kulombik verimlilik ise \% 65'dir. Sn$\mathrm{Cu} / \mathrm{rGO}$ kompozit anot malzemesi için ise ilk deşarj ve şarj kapasiteleri sırasıyla 680 mAhg-1 ve 495 mAhg-1' kulombik verimlilik ise \% 72 'dir. İk deşarj işleminde çok yüksek oranda Li iyonlarının aktif olmasının temel nedeni anot elektrotunun kristalin boyutunun düşük ve yüzey alanının yüksek olması ile ilgilidir [20].Fakat 100 çevrim sonunda ise $\mathrm{Sn}-\mathrm{Cu} / \mathrm{rGO}$ kompozit anot malzemeleri için deşarj kapasitelesi 430 mAhg-1, dir. 

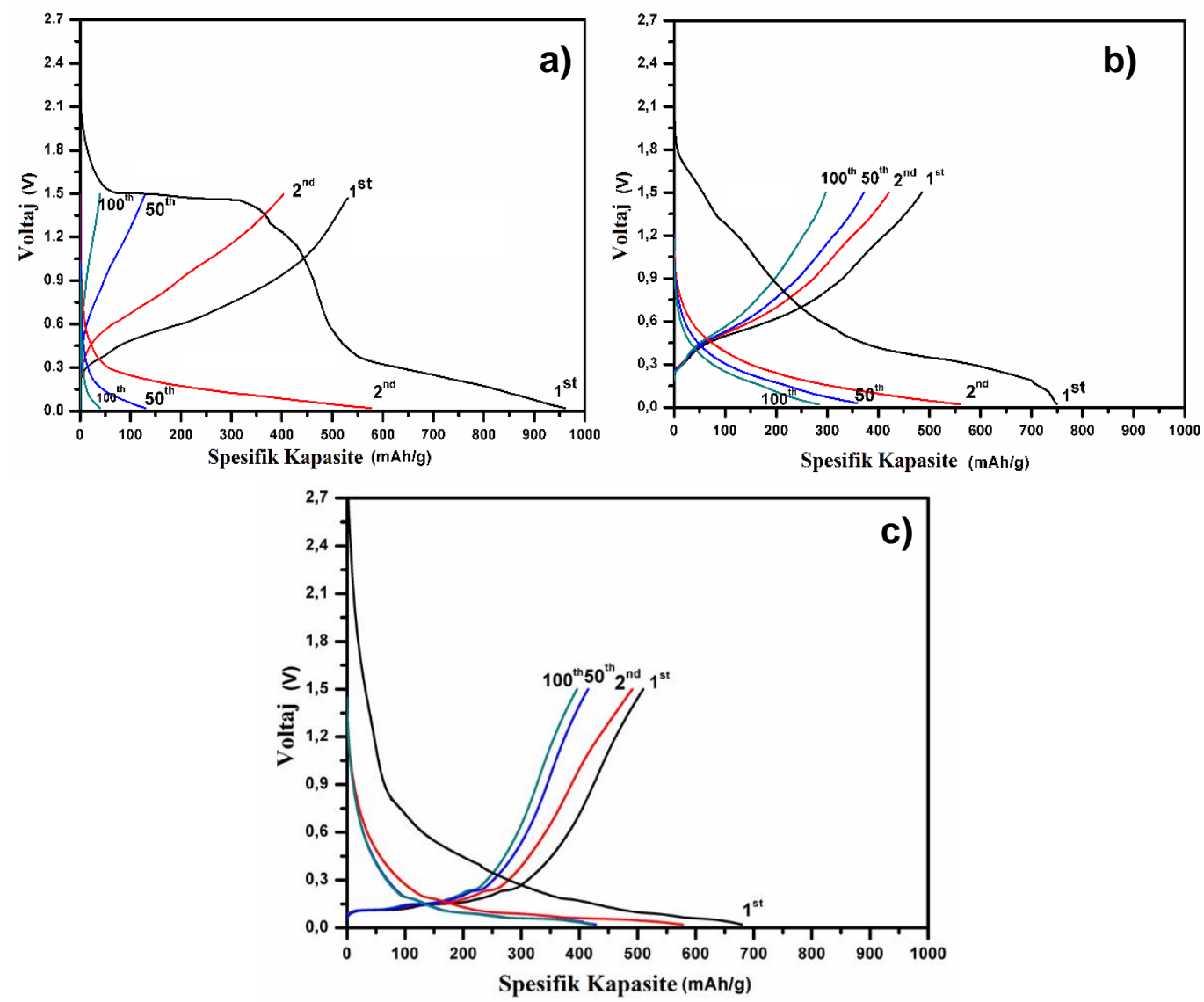

Şekil 5. a) Sn, b) Sn-Cu c) Sn-Cu/rGO elektrotların 1, 2,3 50 ve 100 çevrim için galvanostatik voltaj-kapasite eğrileri

Şekil 6'da Sn, Sn-Cu ve $\mathrm{Sn}-\mathrm{Cu} / \mathrm{rGO}$ tozları ile hazırlanmış elektrotların CR2016 test hücresi kullanılarak sabit $200 \mathrm{~mA} / \mathrm{g}$ akım değerinde $0.02 \mathrm{~V}$ $1.5 \mathrm{~V}$ değerleri arasındaki elektrokimyasal çevrim testi davranışı gösterilmiștir. Şekil 6'dan açık bir şekilde görüleceği üzere saf kalay tozları başlangıçta yüksek spesifik kapasite değerleri göstermesine rağmen, 60 çevrim sonunda kapasitesinin tamamını kaybetmiştir

Şekil 6 incelendiğinde $\mathrm{Sn}-\mathrm{Cu} / \mathrm{rGO}$ kompozit anotların teorik kapasiteye yakın kapasite değerlerinin elde edilmesi, Sekil 2c'deki SEM resimlerinden de görüldüğü gibi, bu yüksek kapasite, morfolojisinden ve gözenekli yapısından dolayı ilk deşarj işleminde çok fazla miktarda Li iyonlarının reaksiyona girmesinden kaynaklanmaktadır. Ancak $\mathrm{Sn}-\mathrm{Cu} / \mathrm{rGO}$ tozlar ile hazırlanan elektrotlar başlangıçta $\mathrm{Sn}$ ve $\mathrm{Sn}-\mathrm{Cu}$ tozlarına göre daha düşük kapasite değeri göstermesine rağmen, 20 çevrim sonunda yaklaşık $440 \mathrm{mAh} / \mathrm{g}$ kapasite değerlerinde sabit ve kararlı bir davranış sergilemiştir. Sn$\mathrm{Cu} / \mathrm{rGO}$ kompozit elektrot 100 çevrim sonunda 430 $\mathrm{mAh} / \mathrm{g}$ spesifik kapasite değeri sergilemiştir. Sn ile kıyaslandığında $\mathrm{Sn}-\mathrm{Cu} / \mathrm{Rgo}$ elektrotlar hem elektrotun iletkenliğinin artmasına hem de hacim değişimi ile meydana gelen elektrotun parçalanma davranışını engellemeye yardımcı olarak elektrokimyasal performansının iyileşmesine yardımcı olmuştur. rGO bu etkisi Qin ve arkadaşlarının ile Peng ve arkadaşlarının daha önceki çalıșmalarında da rapor edilmiştir [21,22]. En ideal sonuçlar $\mathrm{Sn}-\mathrm{Cu} / \mathrm{rGO}$ tozlar ile hazırlanan elektrotlarda elde edilmiş olup kapasite korunumları ise 100 çevrime kadar oldukça yüksek bir oranda olup \% 65 dir.

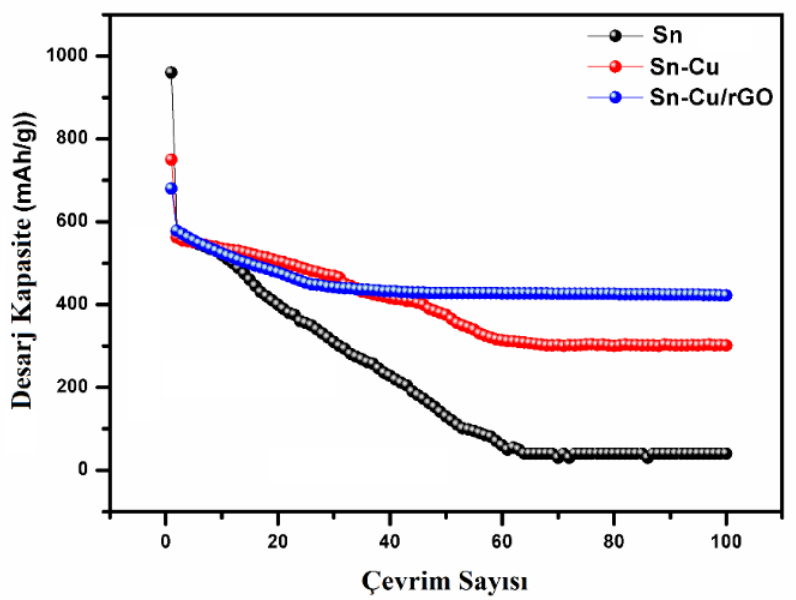

Şekil 6. Elde edilen elektrotların çevrim sayısıdeşarj kapasitesi. 


\section{SONUÇLAR}

Kimyasal indirgeme yöntemi kullanılarak $\mathrm{Sn}, \mathrm{Sn}-\mathrm{Cu}$ ve $\mathrm{Sn}-\mathrm{Cu} / \mathrm{rGO}$ tozlar yaklaşı $50100 \mathrm{~nm}$ boyutunda homojen bir şekilde başarılı bir şekilde üretilmiştir. $\mathrm{Sn}-\mathrm{Cu} / \mathrm{rGO}$ kompozit tozlar hem elektrotta meydana gelen hacim değişiminin bastırılmasına yardımcı olmuş hem de elektrotun iletkenliğini arttırmıştır. Sn ve $\mathrm{Sn}-\mathrm{Cu}$ tozları ile kıyaslandığında daha yüksek spesifik kapasite değerleri elde edilmiştir. Kalay esaslı elektrotlarda indirgenmiş grafen oksit ilavesinin hacimsel genleşmeyi azalttığı ve buna bağlı olarak çok iyi elektrokimyasal performans sağlandığı ispatlanmıştır. Sn-Cu/rGO tozları 100 çevrim sonunda $430 \mathrm{mAh} / \mathrm{g}$ spesifik kapasite değeri göstermiştir. $\mathrm{Bu}$ değer lityum iyon pillerde ticari olarak kullanılan karbon anotların teorik kapasitesinden daha fazladır.

\section{KAYNAKLAR}

[1] Uysal M., Lityum İyon Piller İçin Kesikli Akim Yöntemi İle Kalay Esasli Kompozit Anotlarin Geliştirilmesi Doktora Tezi Sakarya Üniversitesi, Türkiye, 2015

[2] Zhou S., Nanonet-Based Materials For Advanced Energy Storage Doctor of Philosophy Boston College The Graduate School of Arts And Sciences Department of Chemistry, USA, 2012.

[3] Denizli F., Lityum İyon Pilleri İçin Elektron Demeti İle Fiziksel Buhar Biriktirme (Ebpvd) Yöntemi Kullanılarak İnce Film Anot Malzemesi Üretimi Ve Karakterizasyonu Yüksek Lisans Tezi İstanbul Teknik Üniversitesi, Türkiye, 2011.

[4] Alaf M., Lityum İyon Piller İçin $\mathrm{Sn} / \mathrm{SnO} 2 / \mathrm{Knt}$ Kompozit Anotlarının Geliştirilmesi Doktora Tezi Sakarya Üniversitesi, Türkiye, 2014

[5] Leite E.R., Nanostructured Materials for Electrochemical Energy Production and Storage, Springer, New York, 2009.

[6] Subrahmanyam G., Ermanno M., Francesco De A., Enzo Di F., Remo Proietti Z., Claudio C., Review on Recent Progress of Nanostructured Anode Materials For Li-Ion Batteries, Journal of Power Sources 257, 421-443, 2014.

[7] Marom R., Amalraj S.F., Leifer N., Jacob D., Aurbach D., A Review of Advanced and Practical Lithium Battery Materials, Journal of Materials. Chemistry, 21, 9938-9954, 2011.

[8] Wachtler M., Winter M., and Besenhard J. O., Anodic Materials For Rechargeable Li-Batteries. Journal of Power Sources. 105, 151-160, 2002.

[9] Scrosati B., Garche J., Lithium Batteries: Status, Prospects and Future Journal of Power Sources, 195, 2419-2430, 2010..

[10] Junsheng Z., Dianlong W., Tiefeng L.Chenfeng G.Preparation Of Sn-Co-Graphene Composites With Superior Lithium Storage Capability Electrochimica Acta, 125, 347-353,2014
[11] Mao, O., Turnerb, R.L., Courtneya, I.A., Fredericksen, B.D., Buckett, M.I., Krause, L. J., Dahn, J.R., Active/Inactive Nanocomposites As Anodes For Li - Ion Batteries, Journal of Electrochem. Society 2, 3-5, 1999.

[12] Junsheng Z, Guangzhou H, Jin Z Preparation Of $\mathrm{Sn}-\mathrm{Cu}-\mathrm{Graphene}$ Nanocomposites with Superior Reversible Lithium Ion Storage Materials Letters, $185,565-568,2016$

[13] Huan W, Xu L, Montgomery B-F, Placidus B A 3d Graphene-Based Anode Materials for Li-Ion Batteries Current Opinion in Chemical Engineering, 13, 124-132,2016

[14] Xiaoqiu C, Qiang R, Zhen W, Xianhua H, Shejun H Ternary Sn-Sb-Co Alloy Particles Embedded In Reduced Graphene Oxide As Lithium Ion Battery Anodes Materials Letters, 191, 218221,2017

[15] Jizhang C, Li Y, Shaohua F, Zhengxi Z, ShinIchi H Facile Fabrication Of Graphene/Cu6sn5 Nanocomposite As The High Performance Anode Material For Lithium Ion Batteries Electrochimica Acta, 105, 629-634,2013

[16] Zhao H., Jiang C., He X., Ren J., Wan C., Advanced Structures in Electrodeposited Tin Base Anodes for Lithium Ion Batteries, Electrochim. Acta, 52, 7820-7826, 2007.

[17]Junsheng Z, Anmin L, Dianlong W Study On The Synergistic Lithium Storage Performance of Sn/Graphene Nanocomposites Via Quantum Chemical Calculations And Experiments Applied Surface Science, 416, 751-756,2017

[18]Uysal M, Cetinkaya T. Alp A, Akbulut H Fabrication Of Sn-Ni/Mwcnt Composite Coating For Li-Ion Batteries By Pulse Electrodeposition: Effects of Duty Cycle Applied Surface Science, 334, Pages 80-86,2015

[19]Uysal M, Cetinkaya T, Kartal M. Alp A, Akbulut H Production Of $\mathrm{Sn}-\mathrm{Cu} / \mathrm{Mwcnt}$ Composite Electrodes For Li-Ion Batteries by Using Electroless Tin Coating Thin Solid Films, 572, 216-223,2014 [20] Peter, B.G., Bruno, S., Jean-Marie, T., Nanomaterials for Rechargable Lithium Batteries. Angewandte Chemie, 47, 2-19, 2008.

[21] Qin J, He C, Zhao N, Wang Z, Shi C, Ez Liu, Li J Graphene Networks Anchored With Sn Graphene As Lithium Ion Battery Anode, Acs Nano 8 (2), 1728-1738,2014

[22]Peng H, Li R, Hu J, Deng W, Pan F Core-Shell $\mathrm{Sn}-\mathrm{Ni}-\mathrm{Cu}-\mathrm{Alloy}$ Carbon Nanorods to Array As Three-Dimensional Anode by Nanoelectrodeposition for High-Performance Lithium Ion Batteries - Acs Applied Materials, 8 (19), 12221-12227,2016 